\title{
Editorial
}

\section{Sri Lanka Journal of Sexual Health and HIV Medicine (Sri Lanka JoSHH)}

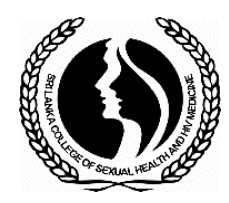

\section{Editorial Board}

Editor-in-chief

Dr Ajith Karawita

MBBS, PgDip Ven, MD, FSLCoSHH

Member of Asia Pacific Association

of Medical Journal Editors

\section{Acquisition editor}

Dr HACW Hathurusinghe

MBBS, PgDip Ven, MD

\section{Assistant editors}

Dr Nalaka Abeygunasekara

MBBS, PgDip Ven, MD, MSLCoSHH

Dr Manjula Rajapakse

MBBS, PgDip Ven, MD

Dr Darshani Mallikarachchi MBBS, PgDip Ven, MD, DFSRH (UK),

Editorial board members Dr Ariyaratne Manathunge MBBS, MSC, MD, FSLCV

Prof Sampatha Goonewardena MBBS, MSc, MD

Dr Jayadarie Ranatunga MBBS, DFM, PgDip Ven, MD

Dr Gayani Nanayakkara MBBS, PgDip Ven, MD

Dr Prageeth Premadasa MBBS, PgDip Ven, MD, DFSRH (UK), Dip in Psychosexual Medicine, FECSM

\section{Secretary}

Dr Nadeera Kumarasinghe

MBBS, PgDip Ven, MD, MSLCoSHH
Sri Lanka College of Sexual Health and HIV Medicine (CoSHH) proudly publishes the volume 6; December 2020 issue of the Sri Lanka Journal of Sexual Health and HIV Medicine (Sri Lanka JoSHH) in both electronic and print media.

HIV estimation and projection in Sri Lanka are more important than ever when the world is trying to reach AIDS free era by 2030. However, being a low prevalent country, and a country which eliminated mother to child transmission of HIV and syphilis in November 2019, Sri Lanka is heading to achieve ending AIDS target by 2025.

AIDS Epidemic Model (AEM) and Spectrum were used as tools to generate the estimates for Sri Lanka. However, results of national estimates indicate that there are 3,600 people living with HIV (PLHIV) in Sri Lanka in 2019. Of this estimate, 3,550 are adults who are 15 years and older, and the male to female ratio was 2.93 . The trend of PLHIV is relatively stable in the past five years implying the state of balance between new infections and AIDS related deaths. Total new HIV infections were estimated at 140 in 2019 with 137 new HIV infections among adults 15 years and older. Although the epidemic is declining in terms of numbers, new HIV infections among men who have sex with men (MSM) is growing. In 2019, 169 AIDS-related deaths are estimated among adults living with HIV. In addition, HIV sentinel surveillance survey $\left(14^{\text {th }}\right.$ round) was conducted in end of 2019. The nine out of nine provinces of the country were identified as 9 sentinel sites and sentinel groups included men who have sex with men (MSM), female sex workers (FSW), clients of sex workers, transgender women and people who inject drugs (PWID). Prevalence of HIV was highest among MSM $(1.46 \%)$ followed by transgender women $(1.35 \%)$ and clients of sex workers $(0.09 \%)$. The prevalence among FSW was $0.07 \%$, and there were no HIV positives cases among the 70 PWID enrolled in the study.

AIDS epidemic in Sri Lanka seems to be under control but not yet over. The question is whether ending AIDS is possible, plausible or a distant prospect? Predicting uncertainties are difficult but it needs concerted efforts from policy, programmes, projects to activities that make individual behaviour change which is scale enough to make the plausible, a reality.

Dr Ajith Karawita

Honorary fellow and the past president (2015-2016) of CoSHH

(D) https://orcid.org/0000-0003-2956-8479

\section{Editor-in-chief}

